\title{
LUMBAR DISC HERNIATION
}

\author{
THE EFFECT OF TORQUE ON ITS CAUSATION AND CONSERVATIVE TREATMENT
}

\section{A PRELIMINARY REPORT}

\author{
Carl W. Coplans, M.R.C.S. (Eng.), L.R.C.P. (Lond.), D. Phys. Med. (R.C.S. \& P.)* \\ Department of Orthopaedic Research, University of Cape Town
}

Reprinted by kind permission of the author, and the South African Medical Journal.

\section{$T^{-1}$} HE surgical approach to the problen of low back pain is of comparatively recent origin and it is salutary, at this time when laminectomy is becoming an increasingly common operation, to consider a new approach to the conservative treatment of lumbar disc herniation.

Before the recognition of lumbar disc pathology as a common cause of low back pain, 'lumbago' was treated by a succession of methods in which empiricism was the common denominator. One of these methods still survives topically and its use in most cases is just as empirical to-day as it was when the pathology of disc herniations was unrecognized. The patient with low backache ineritably submits himself to some form of manipulative procedure either by a registered or unregistered practitioner.

A consensus oi standard works on manipulation shows that the most commonly employed manoeuvre in the treatment of low back pain is the 'pelvic twist'. '. This method is almost universally described and may be performed with or without anaesthesia.

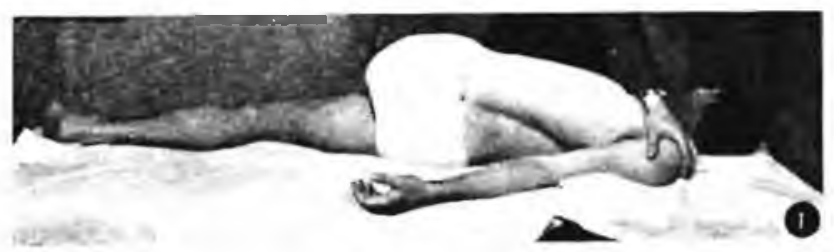

liy. 1. The Felvic Twist. The most commonly emplosed manocurre in manipulation of the spinc.

flice patient lies supine upon a suitably low couch and one shoulder is tixed by the operator's land while the lomolatcral hip is forcibly rotated across the mid-line of the body so that a twist is set up on the spine (Fig. 1). The operator moves to the opposite side of the patient and the same manoeuvre is performed using the contralateral hip and shoulder. This bilateral manipulation is without logical basis and is an empirical relic of the Dark Ages of 'lumbago' when, without critical diagnosis, manipulation was performed for its blunderbuss effect.

Most standard anatomy textbooks are emplatic that little or no rotation take place in the lumbar region of the vertebral column. ${ }^{\text {.' }}$ 'These textbooks further point out that rotation is confined to the thoracic region. Brailsford, ${ }^{8}$ however, following the preparation of a cine $X$-ray film showing the moventents of the spine, states that there is a much greater degree of lumbar

\footnotetext{
* Honorary Specialist in Physical Medicine to the Cape
} Town Free Dispensary and the Somerset Hospital rotation than lias previously been ascribed to this region. X-ray films taken by the author appear to confirm this statement. Blair ${ }^{\circ}$ states that some pure rotation of the lumbar spine does take place, particularly in the lower part of the lumbar vertebrae owing to the laxity of the synovial joints.

A series of $X$-rays was taken to demonstrate thr amount of rotation possible in the lumbar vertebra joints. Two are published in this preliminary communication. Fig $2 \mathrm{~B}$ represents the A-P view of a healthy male of 19 years. The pelvis was fixed and the lumbar region extended; the shoulders were then passively rotated on the pelvis. 'Therc is some slight latero-flexion, but it takes place high in the lumbar spine. It will be seen that rotation increases progressively from $I, 4,3,2$ up to the thoracic vertebrae.

A stationary spine without any attempt at movement is included for comparison (Fig. 2A)

Fig. 3 represents the A-P view of the lumbar spine of a female dancer of 16 years. There is considerably more rotation than in the previous film. There is no latero-flexion. It was taken under the same conditions as Fig. 2 but latero-flexion was avoided by passively controlling the subject's movement.

If iree rotation takes place in the thoracic spine alone, then it must be confined to the lower thoracic spine, since the upper thoracic vertebrae are effectively. splinted by the seven true ribs which, with their direct attachment to the sternum, must limit rotation to some degree. ${ }^{10}$

It is accepted that the costo-transverse and costovertebral joint cxcursion is mainly concerned with respiratory movements.

There exists, therefore, a group of 10 vertebrae which link a relatively fixed portion of the spine (the upper seven thoracic vertebrae) to an absolutely fixed foundation, the sacrum. It is through this link of 10 vertebrae that the torsional forces of rotation must be distributed the main burden of which is felt in the lower lumbar spine where its firm anchorage to the sacrum is encountered. The axis of rotation of the lumbar spine is through the bodies of the vertebrae and it is postulated, therefore, that the intervertebral discs suffer distortion and sustain a great measurc of the torsional strain (hereafter referred to as torque).

It is interesting to conjecture, at this stage, on the functional anatomy of the discs themselves. The inferior surface of one vertebral body is united to the superior surface of the vetrebral body below it by the fibro-cartilaginous disc. The peripheral part of this structure is called the annulus fibrosus and is composed of dense fibro-cartilage. The fibres run obliquely between the two vetrebrae and are arranged in concentrir 


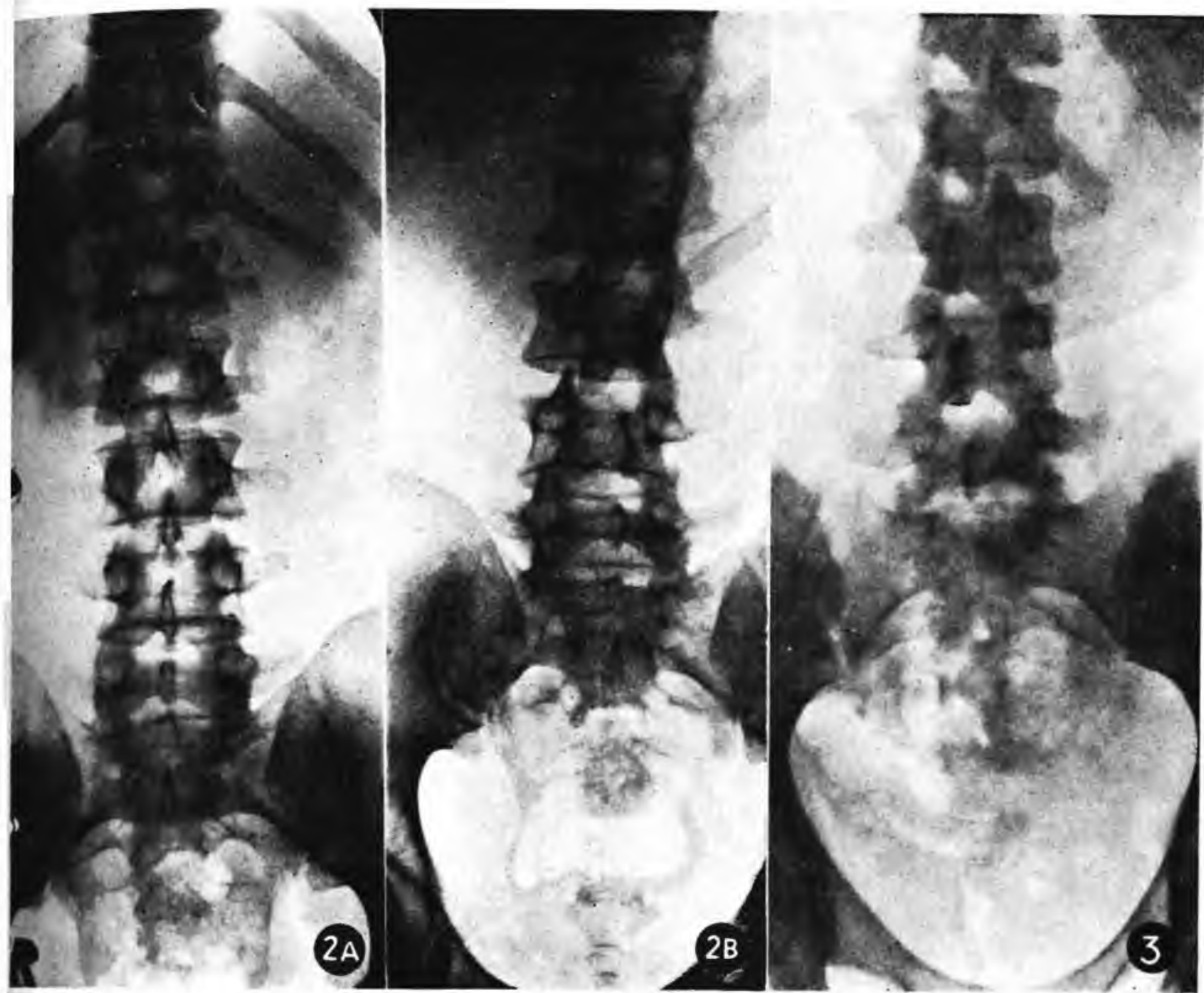

Fig 2. (a) Resting spine. (b) I-umbar vertebrae showing rotation.

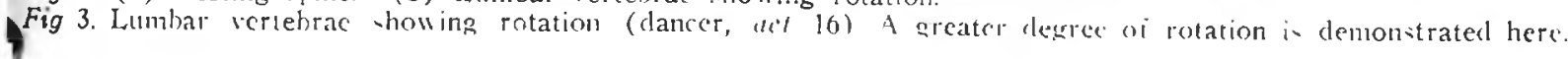

rings, the fibres in succes-ive rings having opposite obliquities.

The central part of the disc is called the nucleus pulposus and is contained in an envelope of fibrocartilage which blends with the inner lavers of the annulus. It is composed of mucoid material interlacerl with fine fibres of fibro-cartilage. On each surlace of the disc, above and below, there is a thin laver of lyaline cartilage. The nucleus is under tension and bulges when the annulus is incised. It is believed that the tension is due to pressure of the clastic fibres of the annulus and not to the expansile force within the nucleus.' ${ }^{2}$ The disc distributes and transmits forces down the spine and allows segment mobility.

It would seem from the mechanical design of the disc that it is well able to adapt itselt to the torque that is thrust upon it. As the force of the torque mounts, the concentric laminae with their fibres running in opposite obliquities would act as a circular spring which winds and unwinds as the torque varie.
111 power and direction. It ceems unlikely that the rotational clement in thoracolumbar vertrebrae, in view. of the enormous forces that it has to sustain, could rease abruptly at an artificially delimited portion of the vine. but rather that the mobile vertebral column woukl clintribute its iorces in relation to its entire architecture. Noreover, the 'shear' force acting on the vertebral hody icnds to rotate the vertebra causing acompression moment of this on the next lower disc."

It is not the purpose of thic paper to emphasize the legrec of rotation that take, place in the lumbar r pinc, but rather to accentuate the torque that is consequent, and which the author belicves is the nost important factor, in the production of disc herniation. Ii thenc mechanics of injury are accepted, then increasing the trammatic torque (i e., the torsional forct that has produced injurs) will cxaggerate pain and lisability. the undermentioned clinical signs become understandable and al-o the principle may he applied in treatment 
Where the diagnosis of lumbar disc herniation has been made, the following two clinical signs should be elicited:

.1. The patient lies supine and the manoeuvre described earlier in this paper as the 'pelvic twist' is performed gently, but with as full a range as the patient's pain permits (Fig. 1).

It will be found that rotation of the pelvis with the homolateral shoulder fixed is invariably more painful to one side than to the other. The direction of the movement causing pain is noted, e.g., right hip rotated to left with right shoulder fixed to the couch, more painful than vice versa.

2. The patient is now put into the prone position and asked to relax as much as possible. Strong lateral pressure is applied by the thumb at right angles to the lumbar spinous processes on one side, commencing at L,1 and working caudally. As the suspected level of herniation. is approached, it will be found that intense discomfort and an increase in root pain (if present) will take placc.

The opposite side is now examined in an identical manner. It will be found that there is little or no intensification of the local or referred pain. The force directed at the sides of the spinous processes should be of a magnitude such as the examiner would. use if he was attempting to elicit movement of the spinous process in the direction of the applied force.

If the two signs are co-ordinated it will be found that :

1. If the right hip rotated to the left with the right shoulder fixed produces pain and vice versa is painless then:

2. Pressure along the left sides of the spinous processes at the level of the herniation will produce pain, the spinous process immediately above the herniated disc bẹing the most painful.

It is important that this pain be differentiated fron paraspinal tenderness. This is due to pressure on the bellies of the erectores spinae which are in reflex spasm following disc herniation. Pain produced by pressure on these muscles is of a more diffuse character and root pain is not increased.

lt is postulated that pressure in the manner described on the sides of the spinous processes, produces a moment of torque upon the vertebra which is in the same direction as the torque produced by the 'pelvic twist.' Both these torsional forces are known as traumatic torque. Torsional force in the opposite direction to the above, is known as 'counter torque' and is utilized. in treatment.

'The author wishes to make it clear that lie does not loold that the torsional stress is the only factor in the production of lumbar disc herniation. $\mathrm{He}$ is well aware of the other stresses that exist, but he regards them as being ancillary to the traumatic torque. It is intended to publish an analysis of the total forces acting on the lumbar spine in the more comprcliensive paper that will follow this preliminary report.

\section{TORQUE, IN TREATMENT}

An important preliminary to treatment is the assessment of the direction of traumatic trorque, which should be done in the manner described above. A

broad padded canvas sling is placed under the patient's chest and a similar one under the knees. The patient is then suspended some two feet above the plinth by means of a Guthrie Smith Suspension Apparatus:

The position of the patient is similar to that which he would occupy if he was having a spinal plaster put on for a fracture of the dorsal vertebrae. In this position the lumbar spine is in extension and consequently, when counter torque is applied, rotation and torsional strain will be effective in this part of the spine. The patient is now placed in counter torque, e.g., if in Sign (1)-right hip rotated to left with right shoulder fixed is painful; and if Sign (2)pressure on the left side of the spinous processes at the suspected level of the disc is more painful than pressure at the same level on the opposite side. Then the patient is slung in counter torque as follows:-

With the patient in prone suspension, the left shoulder is supported so that it points upwards and traction is applied to the left hip so that it is rotated! downwards (Fig. 4).

A special beit' has been designed for this latter purpose. It is applied just above the level of the greater trochanters and buckles above the pubis. The body of the belt encloses a sheet of steel so devised that it allows a rigid rod to slide obliquely from one side to the other; at the free end of this rod, a weight sufficient to produce rotation of the pelvis is attached (Figs. 4-6). The patient's head- is contained in a sling and the left arm is similarly supported. The shoulder and knec slings are now adjusted so that counter torque produces its maximum effect, e.g., left shoulder stay raised, right shoulder stay lowered; left knee stay lowered, right knee stay raised.

An ultra-short wave diathermy drum is applied to the lumbar spinc in order to diminish muscle spasm, and the patient is, left suspended for 20 minutes.

After completion of treatment the patient should be lowered to the plintli witl the utmost gentleness.

This form of therapy may be used for botl acute and chronic lumbar disc herniations. Acute disc herniations are treated twice daily until there is a remission of symptoms and thereafter daily until symptom free. Chronic disc herniations are treated once daily until symptom free. Upon cessation of treatment, counter torque and limbar extension exercises are advised and the patient is fitted with a short Goldthwaite brace. This is worn for a period of two months.

It will be noted that the purpose of this type of suspension is to produce the resultant of two forces upon the lumbar spine. These are:

1. An extension lorce

2. A rotational force

It has been found that counter torque suspension compares very favourably with other morles of conservative therapy. Its success will be evaluated in a more comprehensive paper to be published. It' should be added that in no case have any patients' symptoms been incrcased. 


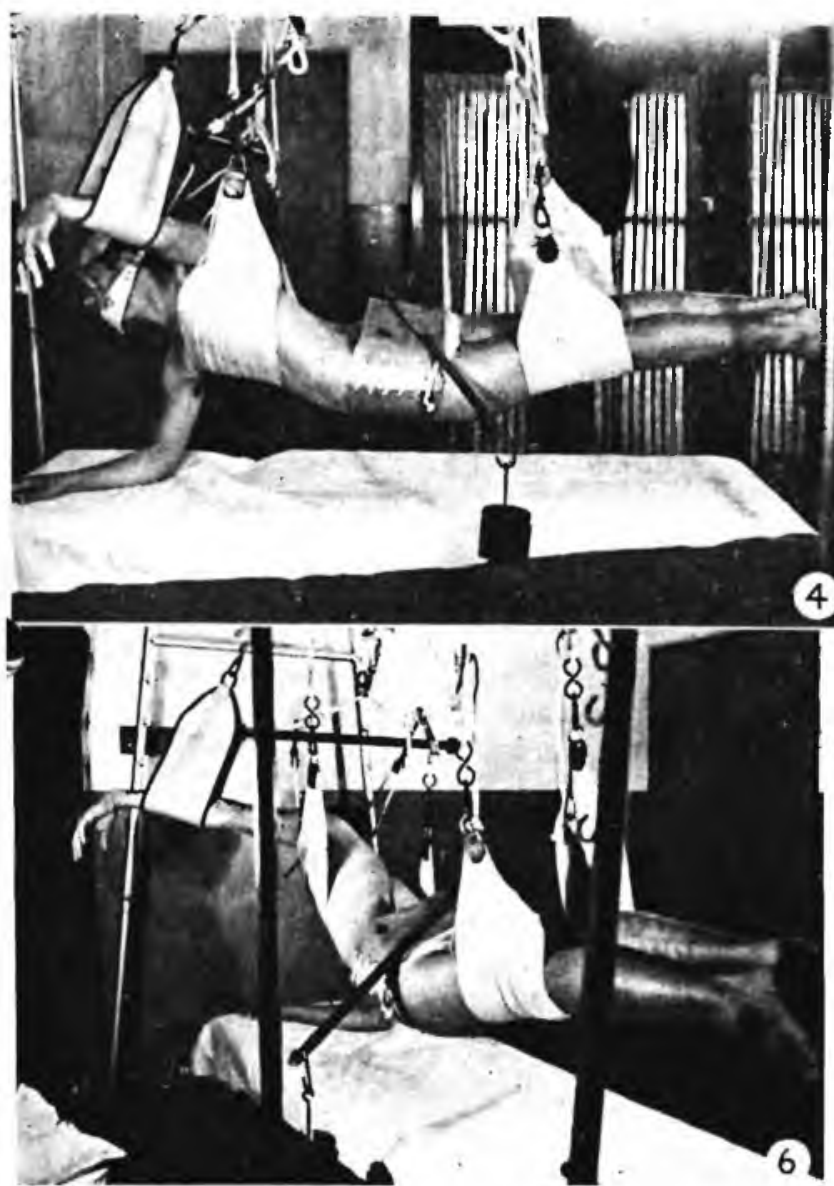

SUMIIAKY

1. 'l'he cliect of torque on the camsation af lumbat dise lecrutations in discussed

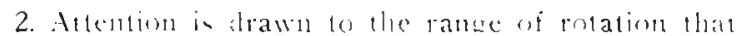
exists in lle lumbate spinc.

3. 'latumatic lorepue is clucielated and two signs fer the recognition of its direction are described.

4. I method oi conservative and ambulant Ircatment known as 'ommler forque suspension' is described.

A traction table, cmbodying hose principles, is nom being constructed.

l'his work lits been done in the Department o: Orblopacdic Kencarch of the Univeruity of Capc Town and I wish to thank $\mathrm{Mr}$. Arthur I. Helfet. MfCle. (Orh.). li.l.C.S. (Jing.) of that Departmen and also Dr. Roland Singer of the l)eparment of Anatomy for lleir collaboration.

A mure comprehensive paper on this subject will be published at a later date in association $\mathbf{W i l l} \mathrm{Mr}$. Helfet and J)r. Singer.

I wisl to thank Drs. $H$. and $B$. Hirschon for the many $X$-rays taken by lhem during the course of this work, Dr. A. Reichlin for his encouragement and advice and Mr. C. MeNintes of the Deparment of

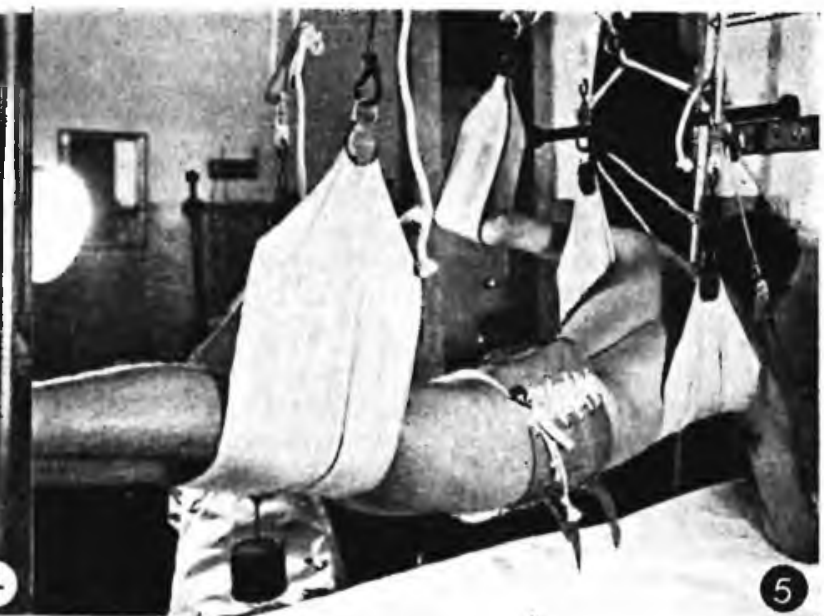

Fis. 4. Coumler Tomque Su-pension. Note the opposite planes of the thoras and pelvis. Torsion nut the

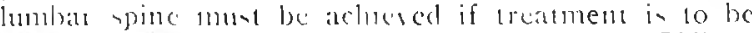
ellective. Fir. 5. Counter Toreque Sumpension. Oblique

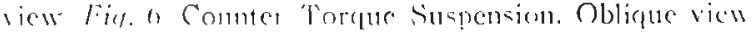

Surkers all (imoote Sehume Hospital for the phomeuraphs.

'The torque belt was made to my design by A. IHodges \& Co. (l'1\%) 1.14., lot Sir Toum Road, Cape 'lown.

\section{REFERINCES}

Ellis, Jolun 1). (1940): 7ho Injured Back and its Treatment. Springfield, lllinois: Charles C. 'Thomas.

2. Mennel, James 13. (1945) : Mhsical Treatment by Moz'ment. Manipulation and Hassagr. London I. \& A. Clunrchill. I,td.

3. Visher, 'limbrell A. C. (194t): Treatment by' Mamipulation. thle ed. I.ondon: H. K. Irewis \& Co, 1.tel.

t. Marlin, 'l. (193t) : Manipulatiac Troblutent for tha Gineral Pratitioner. Iondon: Liward Arnold \& Co.

5. Gray (1938): fuatomy. 27lh ed. Idondon: Longmans, Cireen $\&$ Co.

6. Frazer, Ermest 1. (1933): The Analome of the IIrman Skclitun. I,ondon: I. \& A. Churchill, Ltel.

7. Buchanan (1950): Mamual of Anatomy, sth ed London: Jaalliere, 'linclall \& Cox.

^. Brailstord, James Hi. (19.35): The Radiology of Boncis and joints. Oxiond University Hess.

9. Blair, 1). M. (1937): In Cunninglams \%int Rowk of Anatomy. Oxford Universily Press.

10. Blair, D. M. (1937): Ibid.

11. Blair, D. M. (1937): loid.

12. Spurling, R. G. and Bradford, li. (1939): I. Amer Med. Assoc., 113, 2019.

1.3. Thieme, Frederick P. (1950): Lumbar Braakdown Causcd by lirect Poslure. Anthropological Paper. No. 4. University of Michigan Preas. 